\title{
Means for linking mathematics teaching to mathematics teacher education
}

\author{
Despina Potari ${ }^{1}$
}

Published online: 27 April 2020

(c) Springer Nature B.V. 2020

I am writing this editorial in memory of Prof David Clarke who passed away on the 24 January of this year. His research contributed substantially to our understanding of mathematics teaching as it unfolds in the classroom interaction and of mathematics teachers professional growth through the means of reflection and enactment of teaching. I will try to view the papers of this issue through his lenses, having in mind what he has offered us to study mathematics teaching and mathematics teacher development. David's research had as its main goal the study of the classroom interaction. For him, a "mathematics classroom" is not a specific classroom in a given national and cultural context. It is a mathematics classroom that can be met in different places of the world. Two of his most recent studies indicate the dynamics of the mathematics classroom in two areas, teacher questioning and mathematical dialogue. A variation in teacher's questioning in a classroom in China over a sequence of consecutive lessons showed that teaching also involves teachers' unconscious routine while trying to build the lesson on students' thinking (Dong et al. 2019). Concerning the mathematical dialogue, variations were found in classrooms situated in Shanghai, Seoul and Melbourne, possibly explained by the different cultural values, constraints and affordances that the culture may place in the classroom discourse (Xu and Clarke 2019). David Clarke's research extends beyond the classroom level to teacher education and professional development. In his work with teachers, the classroom interaction becomes the basis of teacher reflection through videos of lessons. In a paper published in JMTE, he and Hillary Hollingsworth (Hollingsworth and Clarke 2017) discuss different ways that video has been used as a way of linking classroom teaching to teacher professional development. In their study, teachers reflect on teaching on the basis of an observation framework and they videotape their lessons focusing on elements of the framework and discuss with researchers about selected video clips showing agency of their own professional learning. Video acted as a catalyst for teacher learning as they could scrutinize into teaching and provide explanations on their decisions and actions.

In the article of Stockero, Leatham, Ochieng, Van Zoest and Peterson in this issue, the focus is on the ways that teachers react to students' thinking in relation to their orientations. The authors used scenario-based interviews requesting teachers to respond to students' ideas provide explanations of their decision and articulate any assumptions they were making that informed it. As in Clarke's research, the focus here is on salient features

Despina Potari

dpotari@math.uoa.gr

Athens, Greece 
of classroom interaction, on students' thinking and on how the teacher can build on it. The authors also extend the existing research on teacher noticing by looking into the underlying reasons for handling students' thinking in certain ways. The means for investigating the links between teacher orientations, students' thinking and how to manage it in the classroom were the classroom scenarios structured in a particular way from the researchers. The scenarios included statements from eight students representing a range of instances of student thinking indicating different forms of thinking based on the authors' theoretical constructs. The findings show different orientations that support or hinder a teacher's practice of building on student thinking. Although the study is rather exploratory and does not aim explicitly on teachers' professional growth, it has implications to teacher education. Knowing which orientations do not lead to productive building on students' thinking and which ones build upon students' thinking is important in differentiating teacher education to meet teachers' needs.

In the study of Swars-Auslander, Smith, Smith and Myers, the mathematics classroom becomes also the focus of attention as the prospective teachers in the context of two teacher education courses select and/or design mathematics tasks with high level of cognitive demand, enact them in the classroom, construct assessment rubrics on the basis of student thinking and reflect on their lessons on the context of interviews and an open ended questionnaire. Different visions of the mathematics classroom are considered in the context of teacher education: the classroom in the context of field experiences, in selected videos clips of students engaged in problem solving and an expected classroom in a public school where often more procedural approaches are adopted. The focus of the study is on the development of prospective teachers' pedagogical beliefs and beliefs on teaching effectiveness in two method courses aiming to integrate the requirements of a state teacher performance assessment (edTPA) in the USA. The difference between the intensions of the courses and the teaching realities in a school classroom seemed to create stress and anxiety to the prospective teachers. They also acknowledged that through the two method courses they learned more about challenging problems, children's understanding and planning teaching and assessment based on children's needs. The findings also show that changing teacher beliefs is more complex than the outcome of a teacher education course as the state teacher assessment conditions have an impact on how prospective teachers feel and act.

Estrella, Zakaryan, Olfos and Espinoza focus on the transformation of a cognitively demanding mathematical task in a third-grade classroom in Chile and on the factors that seem to influence the maintenance or decline of the cognitive demand. An open-ended task on healthy eating with a goal to analyse data was designed and enacted by two teachers in a Lesson Study setting where four primary school teachers and three researchers participated. From the analysis of the first lesson, it was found that in most cases there was decline of the cognitive demand of the task while the maintenance of the demand was scarce. In the second lesson, there was maintenance of the cognitive demand as the teacher was prompting for justification and explanation, using scaffolding, encouraging students to monitor their own progress and providing the opportunity to model high-level performance. The authors argue that the joint reflection in the analysis of the first video lesson promoted teachers' awareness of the maintenance of the cognitive demand and facilitated teachers' decisions and actions that resulted in more instances of maintenance. The study adds to the research on challenging mathematical tasks and their classroom management as it links the process to the context of Lesson Study which provides teachers opportunities to reflect on teaching.

The last article of Jankvist, Clark and Mosvold reports a study on the development of prospective teacher educators' mathematical knowledge for teaching teachers (MKTT) through their participation in a course in the history of mathematics in mathematics education at a 
university in Denmark. In the course, the prospective mathematics teacher educators read and discussed texts addressing the importance of using the history of mathematics in mathematics teaching and mathematics teacher education as well as ways that this can be used. They also designed a mini-project where they used primary sources from the history of mathematics and its use in mathematics education on the basis of their readings. The results show that the three prospective mathematics teacher educators showed epistemological understanding of mathematics while doing connections between the historical source and the modern understanding of concepts. They also noticed meta-discursive rules in their own mathematical activity and potential conflicts of teachers in recognizing these rules. The study offers new insights about the nature of MKTT and its development.

All the articles in this issue look for professional growth of practicing or prospective mathematics teachers as well as of prospective mathematics teacher educators. Reflecting on the Interconnected Model of Professional Growth that Clarke and Hollighsworth (2002) have introduced, I see various dimensions of this model to be met in the four studies. In this model, teacher change occurs in recurring cycles through reflection and enaction in multiple pathways between four different domains, the external domain, the professional experimentation in the domain of practice, the salient outcomes in the domain of consequence and the personal domain. In the study of Stockero et al., interrelationships are built mainly between the personal domain (teachers' orientations), the professional experimentation (how to handle students' responses in the context of the project) and the salient outcomes in the domain of consequences (the inferences and the values that the teachers have from their personal experiences of responding to students). Swars-Auslander et al. see prospective teachers' professional growth through the recurring relations between the personal domain (prospective teachers' beliefs and emotions), the external domain (the two method courses and the state assessment), the professional experimentation (the design, enactment of teaching and the reflection) and the salient outcomes in the domain of consequences (prospective teachers' inferences about the reality of an ordinary classroom). In the study of Estrella et al., an emphasis is given on the interplay of the external domain (the Lesson Study setting), the professional experimentation (designing and enacting the lesson in the classroom) and the salient outcomes in the domain of consequences (valuing the teaching intervention in relation to students' learning). Jankvist et al. consider professional growth through the relation of the personal domain of prospective mathematics teacher educators (the MKTT), the external domain (the assignments of the course), the salient outcomes in the domain of consequences (the values of the epistemological characteristics of mathematics) and the professional experimentation (the mini-project).

\section{References}

Clarke, D. J., \& Hollingsworth, H. (2002). Elaborating a model of teacher professional growth. Teaching and Teacher Education, 18(8), 947-967.

Dong, L., Clarke, D., Cao, Y., Wang, L., \& Seah, W. T. (2019). Teacher questioning practices over a sequence of consecutive lessons: A case study of two mathematics teachers. Sustainability, 11(1), 139.

Hollingsworth, H., \& Clarke, D. (2017). Video as a tool for focusing teacher self-reflection: Supporting and provoking teacher learning. Journal of Mathematics Teacher Education, 20(5), 457-475.

$\mathrm{Xu}$, L., \& Clarke, D. (2019). Speaking or not speaking as a cultural practice: Analysis of mathematics classroom discourse in Shanghai, Seoul, and Melbourne. Educational Studies in Mathematics, 102(1), 127-146.

Publisher's Note Springer Nature remains neutral with regard to jurisdictional claims in published maps and institutional affiliations. 